Motrivivência $\quad$ v. $26, \quad$ n. $43, \quad$ p. $277-286$, dezembro/2014

http://dx.doi.org/10.5007/2175-8042.2014v26n43p277

\title{
ANDANDO SOBRE RODAS NAS AULAS DE EDUCAÇÃO FÍSICA ESCOLAR
}

Daniel Bocchini'

Daniel Teixeira Maldonado²

\section{RESUMO}

Baseado nas teorias pós-críticas da educação, onde o currículo da educação física se configura num campo de construção de significados mais justos e democráticos, esse estudo teve como objetivo relatar uma experiência desenvolvida no primeiro semetre do ano de 2013, sobre a tematização dos esportes com rodas nas aulas de educação física, em uma escola pública do município de São Paulo, com alunos do $7^{\circ}$ Ano. Realizamos práticas pedagógicas que buscaram refletir, questionar, experimentar e compreender tal prática da linguagem corporal. Ao concluir o projeto, percebemos que os alunos alteraram sua percepção em relação aos praticantes de esportes com roda.

Palavras-chave: Educação Física Escolar; Cultura Corporal; Esportes com Rodas

1 Doutorando em Educação/Uninove. Docente de Educação Física da rede municipal de ensino de São Paulo. São Paulo/SP, Brasil.

E-mail: danielbocchini@hotmail.com

2 Doutorando em Educação Física/USJT. Docente de Educação Física da rede municipal de ensino de São Paulo. São Paulo/SP, Brasil.

E-mail: danieltmaldonado@yahoo.com.br 


\section{INTRODUÇÃO}

Na área escolar, a educação física apresenta em sua construção histórica um percurso com muitas discussões, contradições e ressignificações. Apesar de todas as suas especificidades, essas diferentes ideias de se trabalhar as manifestações da cultura corporal buscam em sua essência legitimar a atuação do professor dentro dos muros da escola.

Um dos caminhos que contribuiram sobremaneira para esse reconhecimento se deu através da influência dos estudos das ciências humanas e sociais que trouxeram uma perspectiva mais integral as aulas, que até então limitavam a compreensão biológica e psicobiológica. Considerando a realidade socio-cultural dos alunos, essa visão atribui à gestualidade um caráter de linguaguem, ou seja, por meio dos gestos, nos comunicamos com as pessoas e expressamos nossas intenções, desejos e expectativas, assim, os discursos produzidos assumem a função de estruturar e organizar a circulação dos significados (GONÇALVES, 1999 e NEIRA e NUNES, 2009).

Podemos claramente perceber como a linguagem corporal se manifesta em nossa sociedade como exemplo através das expectativas de comportamentos esperados entre homens e mulheres a partir da maneira de falar, sentar e andar ou quando observamos alguém cabisbaixo que pode simbolizar uma tristeza ou cansaço, enfim, cotidianamente nos comunicamos, assim, assumimos diferentes posições que contribuem para organizar a teia social. Dentre os códigos que compõem a linguagem corporal destacam-se as danças, brincadeiras, jogos, lutas, esportes e etc, é importante notar que esses gestos contribuem para a formação da identidade cultural do indivíduo e do grupo que pertence.

Com sua base na teorização Crítica e Pós-Crítica ${ }^{3}$ do currículo a educação física escolar deixa de concentrar seu foco apenas nas questões procedimentais, motoras ou físicas e passa a integrar nas suas discussões pedagógicas termos como cultura, discurso, alteridade, identidade/ diferença, multiculturalismo, saber/poder, entre outros. Em outras palavras, podemos dizer que área despertou, assim como as demais, para compreender o papel central que o currículo assume nos atuais debates da educação, pois, perde a característica de ser algo neutro e posto e ganha o status de um importante elemento que contribui na construção daquilo que somos e daquilo que iremos nos transformar (NEIRA e NUNES, 2008). Apoiado nessa teoria, Canen e Oliveira (2002, p. 61), apontam que o currículo pautado na perspectiva da cultura "valoriza a diversidade e questiona a própria construção das diferenças e, por conseguinte, dos estereótipos e preconceitos contra aqueles percebidos como 'diferentes' no seio de sociedades desiguais e excludentes".

3 “A teoria pós-crítica entende que as relações de poder não são tão centralizadas, como prega a visão crítica cuja ênfase é quase exclusiva na relação entre classes sociais. Nesse novo entendimento, o poder se torna descentrado, ou seja, amplia-se o mapa das relações sociais e com isso são envolvidas relações gênero, etnia, raça, religião e sexualidade (BOCCHINI, 2012, p. 62)". 
A partir desse entendimento, as aulas de educação física que não possibilitam um olhar além da prática, através de uma perspectiva crítica, podem favorecer a reprodução dos pressupostos da sociedade capitalista e da visão dominante, pois, na medida em que o professor possibilita aos educandos uma abordagem pedagógica que se restringe a determinados conteúdos (no caso da educação física o "quarteto mágico" futebol, voleibol, basquetebol e handebol) não propondo nenhuma discussão e análise crítica dessas práticas ele pode corroborar para uma leitura limitada e pobre da realidade, assim, perpetua e fortalece visões discriminatórias e preconceituosas a determinadas práticas corporais, etnias, raças, gêneros, opções sexuais e religiões. Em seus estudos, Vago (1997, p. 90) nos ajuda a elucidar essas questões dizendo:

"Com essas indicações, enfim, defende-se a organização de uma prática escolar de Educação Física, nas séries iniciais do ensino fundamental, que considere, respeite, investigue e enriqueça a construção sociocultural da corporeidade humana de cada uma e de todas as crianças que estão na aula. Tal construção é ampliada nas relações sociais que as crianças estabelecem com a cultura, em lugares sociais como a casa, a rua e na própria escola. É para essa construção que a Educação Física deve contribuir com a sua prática escolar."

No intuito de trazer novas possibilidades pedagógicas, frequentemente presenciamos professores criticarem a predominância do "quarteto mágico" nas aulas e tentam propor mudanças tematizando conteúdos diferenciados tratados como projetos, atividades esporádicas ou comemorativas que fogem ao padrão como: badminton, capoeira, maculelê, artes circenses, ginásticas artística, entre outros. $\mathrm{Na}$ medida em que observamos os relatos dessas práticas é comum o foco didático se concentrar apenas no conhecimento histórico e no aspecto procedimental da manifestação. Essa ação é chamada por Torres Santomé (1998) de currículo turista, pois nessa perspectiva os conhecimentos são tratados a partir de informações rasas e sem contextualização, fato que muitas vezes só contribui para naturalizar o preconceito a certas manifestações da cultura corporal, e, consequentemente a determinados grupos sociais.

Há algum tempo Daolio (1995) diz que a educação física sempre teve dificuldade de lidar com as diferenças manifestadas pelos indivíduos, assim, o tratamento adotado foi de silenciar, neutralizar e excluir, sentindo-se através da padronização e da homogeneização mais segurança. Mandarino (2010, p. 51) nos esclarece dizendo que:

"[...] a escola tenta demarcar esta diferença de quem foge da norma, mas não a fuga da diferença étnica, religiosa, de gênero, classe social, etc., porque isto parece importar menos. Justamente nas diferenças culturais que representam a fronteira entre o que é do gênero masculino e do gênero feminino, produzidas nas aulas de Educação Física, parecem não se tornar um elemento para se pensar a in/exclusão sobre o que é feito por um e não pelo outro. O que separa os gêneros? A questão biológica, a aptidão física, habilidades motoras, os interesses por determinadas práticas desportivas? Como pensar num método de ensino que permita a aprendizagem dos escolares, se no seu princípio já foi definido que devem aprender em grupos separados? Já lhes foi negada, na sua origem, a tentativa de desenvolver uma proposta pedagógica em que ambos estejam juntos." 
Tendo como referência a pluralidade cultural que permeiam a escola e as aulas de educação física, o professor em sua prática pedagógica deverá proporcionar aos educandos a possibilidade de acessar o maior número de manifestações que compõem a cultura corporal. Assim sendo, nessa concepção o objetivo das aulas é proporcionar aos educandos chances de reconhecer, socializar, ressignificar e ampliar os sistemas de significação das diversas culturas através da linguagem corporal (São Paulo. Secretaria Municipal de Ensino, 2007).

$\mathrm{Na}$ tentativa de construir nas aulas um caminho mais democrático e justo, inicialmente, é essencial que o professor tenha a consciência do seu papel político dentro da escola, é através de sua ação, compartiIhada com toda a comunidade escolar, que se podem vislumbrar novos ares.

Como docentes da rede pública, portanto, sabedor de todas as dificuldades que cotidianamente o professor atravessa em sua jornada, como exemplo a falta de apoio da equipe gestora, falta de material, falta de espaço, salas lotadas, alunos indisciplinados, pais ausentes, baixos salários, saúde fragilizada e etc, buscamos com esse artigo, compartilhar com os prezados colegas um projeto cuja tematização foram os esportes com rodas, com o intuito que esse relato possa oferecer ao leitor a possibilidade de vislumbrar e refletir uma prática pedagógica que vise contribuir para a formação crítica dos educandos.

\section{Relato da experiência}

O objetivo deste texto é relatar uma experiência sobre a tematização dos esportes com rodas nas aulas de Educação Física em uma escola do município de São Paulo, localizada na zona norte, no bairro Freguesia do Ó, com os alunos do $7^{\circ}$ Ano. As aulas foram ministradas durante o $1^{\circ}$ semestre do ano de 2013.

Relatos de práticas docentes são registros de atividades realizadas com os alunos, com o objetivo de construir conhecimentos. Neles deve transparecer a intenção do professor em cada atividade planejada, suas reflexões e observações ao longo do desenvolvimento da experiência. O caminho para alcançar cada objetivo precisa estar claramente expresso, para que os leitores, provavelmente outros professores, possam compreender o trabalho por inteiro. Os resultados alcançados e o modo como cada procedimento foi avaliado, retomado, revisto, refeito também precisam estar explícitos, de modo a propiciar elementos de análise para posterior reflexão e busca de caminhos, na perspectiva da melhoria contínua da educação oferecida na escola (DELMANTO; FAUSTINONI, 2009, p. 9).

A ideia de trabalhar essa temática surge a partir de três motivos, o primeiro refere-se à frequência que observamos os alunos, quando estamos a caminho da escola, brincando com bicicletas, skates e patins nos arredores da escola, assim, constatamos que de certa maneira essas práticas fazem parte de sua realidade socio-cultural. O segundo é devido ao fato estar atrelado aos objetivos propostos pelo PEA - Projeto Especial de Ação - onde, no ano de 2013, em reunião, foi estabelecido que a unidade escolar iria tratar das manifestações da cultura. O último motivo se deu após uma reunião do Conselho da Escola, que debateu sobre algumas questões do trânsito local, como a escola é situada numa rua sem saída, em determinados horários como na hora 
de entrada e saída de alunos, observamos uma grande confusão entre carros, perua escolar, pedestres e alunos que disputam um espaço no meio da rua, já que a calçada há tempos encontra-se intrasitável devido a um monte de entulhos que impedem o trânsito dos pedestres, frente a esse caos, entendemos que essa questão seria muito importante para ser discutido no projeto de esportes com rodas.

Para iniciarmos o projeto realizamos um levantamento sobre que os alunos conheciam dos esportes com rodas, diagnosticamos que além de terem um conhecimento restrito a apenas modalidades como o skate, patinete, patins e bicicleta seus discursos atribuiam a prática desses esportes a determinados grupos sociais, como por exemplo, quando um aluno disse que patins era uma atividade mais voltada para o sexo feminino, em contrapartida, o skate era visto como um esporte masculino. Vale ressaltar que no primeiro dia do projeto, quando avisamos os alunos sobre o tema foi interessante notar a empolgação com a proposta, eles não esperavam que na escola fosse local para andar de skate, patins, bicicleta e patinete.

Após as informações coletadas realizamos um plano de ações didáticas que tinham o objetivo de atender às expectativas de aprendizagem selecionadas a partir do caderno de Orientações Currículares. As expectativas eleitas foram:

- Conhecer a história específica da modalidade investigada, relacionando com seu contexto histórico e possíveis influências nas atividades de aula.
- Identificar possíveis relacões de poder presente nas práticas (local e global), sugerindo propostas para democratizar as relações.

- Analisar criticamente o papel da mídia e os efeitos sobre os apreciadores/consumidores das práticas esportivas.

Na segunda etapa do projeto, realizamos a vivência das modalidades. Perguntamos aos alunos quais esportes com rodas eles praticavam e se poderiam trazer para a escola, comentaram que havia a possibilidade de trazer skate, patins, patinete e bicicleta, então, combinamos que iriamos explorar cada material em uma aula.

Iniciamos as aulas práticas com o skate. Num dia estavamos a caminho da escola e nos deparamos com dois adolescentes andando de skate na rua, perguntei se eles queriam realizar uma apresentação de algumas manobras para os alunos, prontamente aceitaram. No dia da aula prática de $s k a t e$, esses dois adolescentes realizaram diversas manobras e deram dicas para os iniciantes, logo depois, deixamos que os alunos vivenciassem a modalidade.

Conforme o combinado nas outras aulas os alunos vivenciaram as outras modalidades. De uma maneira geral, podemos avaliar que as aulas tiveram a participação da grande maioria da turma, como não possuiamos materias para todos foi interessante notar, sem qualquer interferência nossa, a forma com que eles se organizaram no empréstimo do material aos colegas, além disso, vale destacar também a ajuda entre os próprios alunos para realizarem a dinâmica. 

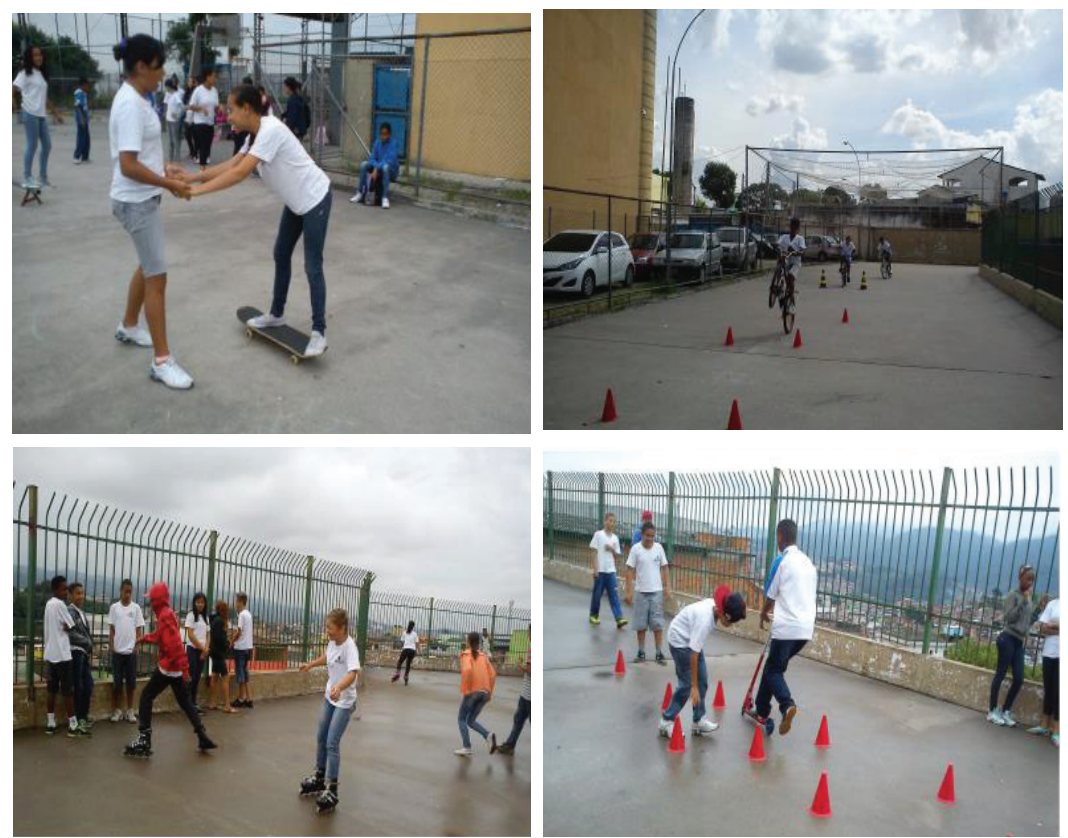

Figura 1: Alunos realizando as vivências de bicicleta, patins, skate e patinete.

Na próxima ação, realizamos análises de várias reportagens e vídeos divulgados pela a mídia que traziam uma representação esteriotipada dos praticantes de alguns esportes com roda. Então, procuramos compreender o porquê alguns indivíduos sofrem preconceitos pelo simples fato de andar de bicicleta, skate, patins e etc. Assistimos alguns vídeos mostrando a violência que esses praticantes sofrem pela polícia por praticarem esses esportes, como no exemplo ocorrido na Praça Roosevelt, localizada na cidade de São Paulo, onde gratuitamente policiais agrediram skatistas e patinadores. Discutimos que, provavelmente, esses discursos acontecem por essas modalidades esportivas serem praticadas na rua, ou seja, como existem poucos locais públicos destinados a sua prática ruas, parques e praças acabam se tornando os locais onde é possivel ver pessoas andando de skate, patins e bicicleta, consequentemente, muros, corrimãos e escadas se tornam interessantes lugares para realizarem as manobras. Analisamos também que as músicas que esses praticantes ouvem, em geral rock e rap, e sua vestimenta, normalmente largas para facilitar os movimentos, são visto pelas pessoas com muita discriminação e esses acabam se tornando sinônimo de maloqueiros, drogados e desocupados. 

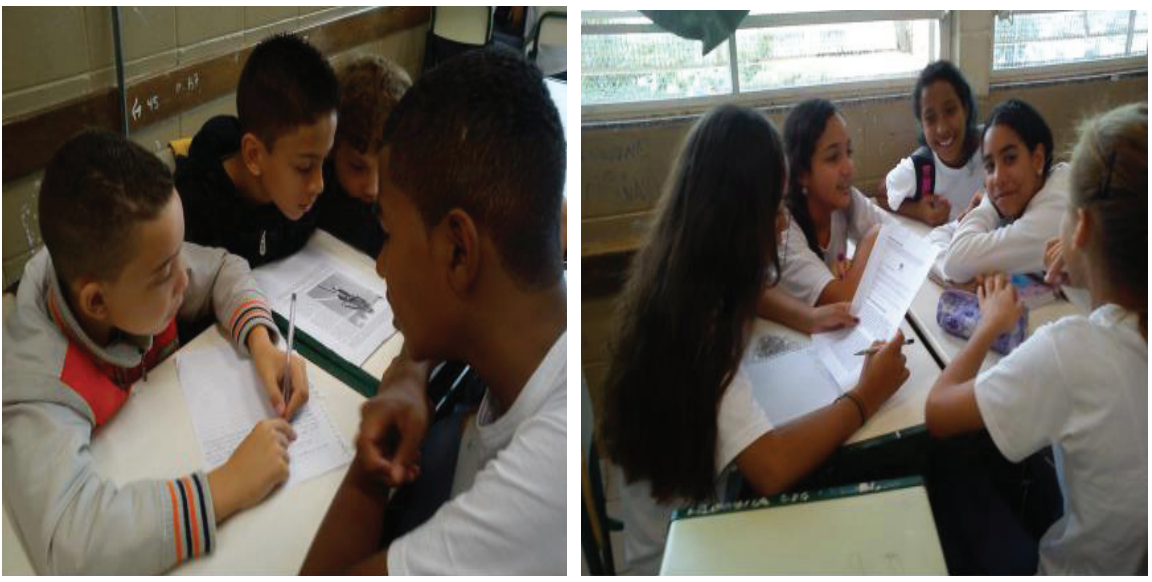

Figura 2: Alunos realizando as análises das reportagens.

Aproveitamos o debate para discutir também algumas questões relacionadas ao preconceito em relação ao gênero, pois como havíamos observado no inicio do projeto alguns alunos possuiam uma visão preconceituosa com relação à prática feminina de alguns esportes com roda, além do skate comentamos sobre o automobilismo que é predominanemente dominado pelos homens, analisamos essa realidade sob a perspectiva da diferença de criação entre os sexos onde é comum observar que o homem tem mais oportunidade de explorar determinadas atividades consideradas radicais ou perigosas, já as mulheres acabam sendo mais reprimidas nessa questão, aquelas que se aventuram transgredindo esse ideal são vítimas de fortes descriminação. Isso pode explicar, em partes, o predomínio masculinos nos esportes com rodas.

Devido ao problema do trânsito local debatido no conselho de escola e pelo fato de observamos que a maioria dos alunos possuiam bicicletas resolvemos nos aprofundar um pouco nessas temáticas, então, utilizamos como suporte para a nossa discussão duas dissertações, a primeira fala sobre a mobilidade urbana e os fatores que influênciam o uso da bicicleta nas cidades e a segunda discute a questão do uso da bicicleta como um transporte sustentável. Durante a conversa sobre esse tema, em meados de maio e junho de 2013, eclodiram em todo o país várias manifestações contra o aumento do transporte público, esse assunto também foi muito discutido nas aulas, procuramos compreender a relação que existe entre os interesses do governo, a mobilidade urbana, transporte público e o uso da bicicleta como um meio de transporte sustentável.

No sentido de contribuir ainda mais para o debate selecionamos alguns vídeos que falavam sobre alguns acidentes envolvendo ciclistas, inclusive, lembramos um caso bem recente de um jovem com 21 anos que foi atropelado na Avenida Paulista, em São Paulo, e teve seu braço arrancado por um carro. Encontramos um documentário chamado "Vou de bicicleta", 
que foi exibido por um jornal televisivo, retratando a vida das pessoas que se aventuram cotidianamente no trânsito paulistano utilizando a bicicleta como um meio de transporte, nesse vídeo é dabatido as leis de trânsito existentes que contribuem para regulamentar o uso da bicicleta.

Durante um horário de intervalo o professor de português da escola nos indagou sobre algumas bicicletas que havia visto com os alunos na escola, então, expliquei sobre o projeto que estávamos desenvolvendo, então, ele começou a nos contar que era ciclista e participava de diversas provas de endurece, provas de longa duração. Então, para finalizar o projeto nos convidamos o professor para fazer uma palestra que contasse aos alunos um pouco sobre sua experiência com o ciclismo e as provas que participa, no dia combinado, para enriquecer ainda mais, gentilmente, ele trouxe para os alunos conhecerem dois tipos de bicicleta diferentes, uma para asfalto e a outra para terra, além de vir com a roupa que os ciclistas utilizam para pedalar. Foi um momento muito interessante porque, inicialmente, nenhum aluno imaginava que o professor de português fosse um ciclista esse fato surpreendeu a todos, também foi muito importante a contribuição do debate que contribuiu para refletirmos sobre mais questões relacionadas ao uso da bicicleta.

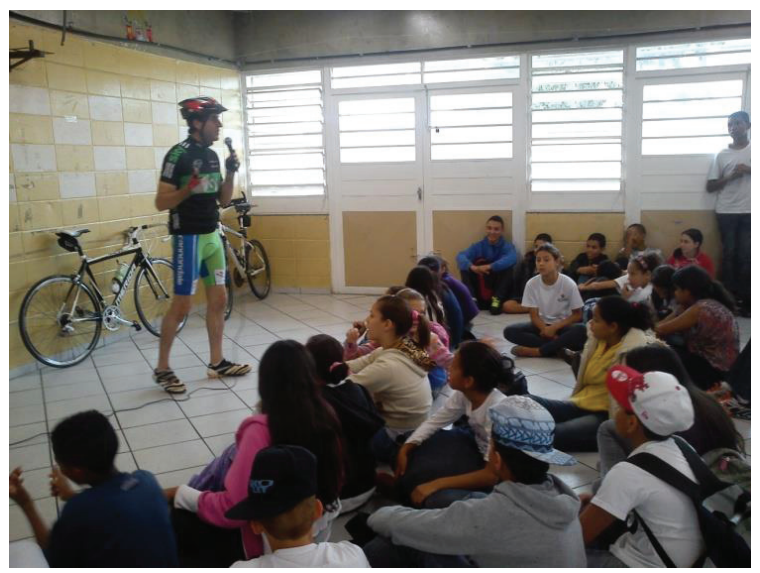

Figura 3: Palestra do professor Weber

\section{CONSIDERAÇÕES FINAIS}

Ao final do projeto, conseguimos identificar que os alunos começaram a refletir sobre os esportes com rodas de outra maneira, as aulas práticas, análise de vídeos e reportagens e os debates contribuiram para que os alunos pudessem construir outras representações em relação aos seus praticantes.

Observamos que os alunos gostaram bastante de estudar esse tema, participando ativamente de todas as etapas, apesar de alguns terem resistência a aulas não 
práticas, isso ainda pode ser reflexo de uma educação física que se caracteriza por uma prática acrítica.

Durante a execução do projeto encontramos diversos obstáculos como o pouco material disponível para uma sala com um número grande de alunos, espaços inadequados para a realização das aulas práticas e resistência de alguns alunos com o novo tema que não estavam acostumados nas aulas.

Através das ações didáticas foi possível refletir, reconhecer e valorizar os esportes com roda com um patrimônio da cultura corporal. Com isso, sugerimos que outros professores também relatem suas experiências pedagógicas para que possamos a partir dessa troca proporcionar aos educandos uma educação física mais democrática e crítica.

\section{REFERÊNCIAS}

BOCCHINI, D. Indentidade e alteridade na prática pedagógica na educação física escolar. Dissertação (mestrado) - Universidade São Judas Tadeu, São Paulo, 2012.

CANEN, A.; OLIVEIRA, A.M.A. Multiculturalismo e currículo em ação: um estudo de caso. Rev. Bras. Educ., n. 21, p. 61-74, 2002.

DAOLIO, J. Da cultura do corpo. Campinas: Papirus, 1995.

DELMANTO, D.; FAUSTINONI, L. E. Os relatos de prática e sua importância no processo de produção e socialização do conhecimento. In: GOIÁS. Secretaria de Estado da Educação. Reorientação curricular do $6^{\circ}$ ao $9^{\circ}$ ano: currículo em debate - Relatos de Práticas Pedagógicas. Goiânia: SEE/GO, 2009.

GONÇALVES, M. A. S. Teoria da ação comunicativa de Habermas: Possibilidades de uma ação educativa de cunho interdisciplinar na escola. Educação \& Sociedade, ano XX, $n^{\circ}$. 66, Abril, 1999.

MANDARINO, C. M. Sitiamentos sobre a in/exclusão na educação física escolar. IN:CHICON, J. F; RODRIGUES, G.M (Orgs). Educação Física e o caminho da inclusão. Vitória/ES: Ed. Edufes, 2010.

NEIRA, M; NUNES, M. L. F. Pedagogia da cultura corporal: críticas e alternativas. São Paulo: Phorte, 2008.

- Educação Física, Currículo e Cultura. São Paulo: Phorte, 2009.

SÃO PAULO. SECRETARIA MUNICIPAL DE ENSINO. Orientações curriculares e proposição de expectativas de aprendizagem para o Ensino Fundamental: ciclo II: Educação Física. São Paulo: SME/DOT, 2007.

TORRES SANTOMÉ, J. Globalização e interdisciplinariedade: o currículo integrado. Porto Alegre: Artmed, 1998.

VAGO, T. M. Das escrituras à escola pública: a educação física nas séries iniciais do ensino fundamental. In: SOUSA, E. S. e VAGO, T. M. Trilhas e partilhas: educação física na cultura escolar e nas práticas sociais. Belo Horizonte: UFMG, p. 59-92, 1997. 
WALKING ON WHEELS IN SCHOOL PHYSICAL EDUCATION CLASSES

\begin{abstract}
Based on the post-critical theories of education, where the curriculum of physical education represents a field of building more just and democratic meanings, this study aimed to report a semester developed in the first year experience of 2013, on the themes of sports wheeled in physical education classes, in a public school in São Paulo, with students from Year 7. Performed pedagogical practices that sought to reflect, question, experiment and understand the practice of body language. To complete the project, we realized that students changed their perception of the practitioners of sports with wheel.
\end{abstract}

Keywords: Physical Education; Corporal Culture; Sports with Wheels

\title{
ANDANDO SOBRE RUEDAS EN LAS CLASES DE EDUCACIÓN FÍSICA ESCOLAR
}

\section{RESUMEN}

Basado en las teorías pos-críticas de la Educación, donde el currículo de la Educación Física se configura en un campo de construcción de significados más justos y democráticos, ese estudio tuvo como objetivo relatar una experiencia desarrollada en el primero semestre del año de 2013, sobre la tematización de los deportes con ruedas en las clases de Educación Física, en una escuela pública del municipio de São Paulo, con alumnos del $7^{\circ}$ grado. Realizamos prácticas pedagógicas que buscan reflejar, cuestionar, experimentar y comprender tal práctica del lenguaje corporal. Al concluir el proyecto, percibimos que los alumnos alteraron su percepción en relación a los practicantes de deportes con ruedas.

Palabras clave: Educación Física escolar; Cultura corporal; Deportes con ruedas

Recebido em: fevereiro/2014

Aprovado em: junho/2014 